\title{
POLITICAL AND SOCIAL INFLUENCES ON FASHION IN 1930S
}

Rabab Ahmad AL-RIFAI *

Fashion Department, The High Institute Of Applied Arts, $6^{\text {th }}$ October, Egypt

\begin{abstract}
In the early twentieth century, the world witnessed important political, economic and social transformations and changes that had the greatest impact on the process of development of societies and defining their female characteristics and their distinctive features. The decade of the thirties was one of the most important historical periods in that period due to the characteristics and features it witnessed in political and social changes such as the collapse of the global stock exchange in The year 1929 led to the great global economic depression, which led to a period of austerity with the cessation of industrial business - commercial agriculture and the cessation of the movement of sale and purchase, unemployment, hunger and standing hours to get a loaf of bread, and the socio-historical method of studying art proved that there is a close connection between The political, economic and social conditions prevailing in a society.

Keywords

Political, Social, Influences, Fashion.
\end{abstract}

\section{Introduction}

among the basic features of the culture of these groups, including art in its various types, given that the product of the human spiritual culture is a form of human consciousness and because man is not an isolated individual and is linked by many strings to the society that He lives in it, his spiritual and mental life appears as a social phenomenon and the collective consciousness of the individuals who live in this area In this sense, it can be said that political, economic and social changes in the life of societies directly affect art in general and fashion in particular, which is an objective reflection of these changes. This may be a new trend of fashion in the thirties, influenced by the political and social conditions surrounding it, and an attempt to escape from the painful reality, a fashion that expresses the woman's inheritance and increases her charm and attractiveness, for those who could afford it and deal with it, and the other side is only following.

\section{Research Problem:}

1- The ability of references on fashion and the history of fashion in the 1930s.

2- Despite the multiplicity of studies in the field of fashion that have dealt with it from many aspects, an integrated vision has not yet been presented. It is based on analyzing the history of fashion and fashion through a political, economic and social perspective to prove that interactive relationship between these factors and between The fashion present in a certain historical period is betrayed by historical errors. Study of fashion far from the history of the truth. Fashion is not an isolated island and it is an objective reflection of these variables. This

* Corresponding author: info@appliedarts.edu.eg 
could contribute to providing designers and fashion professionals with a new dimension, an inexhaustible source for inspiring heritage and opening new horizons for predicting future trends in the field of fashion.

\section{The First Axis:}

Study of the political and social conditions in the thirties of the twentieth century: The occurrence of economic crises in capitalist countries is due to the fact that the free system refuses the state to intervene to limit the activity of individuals in the economic field, so the owners of capital are free in how to invest their money and business owners are free in what they produce in quantity and quality. This is what we might call a loss of control and direction. Economic freedom entails freedom of competition between the producers of the same type of commodity, and the introduction of the machine into the economic process would double production and reduce the need for manpower, and thus the surplus production needs markets for disposal, and when the relationship between supply and demand is disrupted in the absence of control An economic chaos occurs, the inevitable result of which is a crisis within the capitalist state, and one of the causes of the crisis in the United States of America is the instability of the economic situation and the policy of intensity of production to cover the needs of global markets during the First World War due to the stoppage of factories in some European countries after their transformation into military production and the return of many countries to production After the end of the war and dispensing of American goods. For these reasons, goods piled up in the United States, accumulated debts, many factories and factories went bankrupt, workers were laid off, unemployment spread, purchasing power weakened, and social and moral problems worsened at the time. In addition to that, those European countries had the effect of repaying the debts owed by them to the United States of America. American and foreign investors gained confidence in the US Treasury. This was reflected on the New York Stock Exchange "Wall Street" on October 24, 1929, all of which led to panic in the stock exchange and a major fall in its prices. It was the starting point for a financial crisis that affected a large part of the world and lasted until 1933 - when the shareholders of the major companies offered their shares for sale intensively. This led to a sharp drop in stock prices and led to more bankruptcy, layoffs and unemployment. This is in addition to a terrible drought in the midwestern United States of America, which led to poor crop production and farmers 'inability to pay interest on their debts to banks, which in turn led to the bankruptcy of a large number of banks. On the first of October 1931, 31 banks were seen bankrupt in one day. This is how the major economic crisis was a result of the results of the First World War and a reason for the outbreak of World War II. The economic crisis affected the social classes, especially the middle 
class, which lost all their savings when they became bankrupt. The banks, as for the working class and the poor, the situation was worse and people lost their jobs, the unemployment rate increased, they lost their homes and their savings, and schools stopped, in addition to the decrease in the rate of marriage and childbearing. And it was postponed until conditions improved and due to the great impact of the crisis on societies. The political culture grew in them and they took care of or followed the events that are directly related to daily life and a social achievement appeared during this period that helps the financially inexpensive escape from the economic crisis through radio, cinema and reading books. Hollywood has provided A picture of the pictures of this escape to the community during that period through films depicting the societies of the upper classes and in which they embodied comfort, tranquility and luxury, so her blood stars and movie stars added to her pleasure and magic. Escape also appeared in participation in various sports, team games, and home games such as "Monopoly." Economic reform did not begin in the United States until 1933 with the New Testament policy set by President Franklin Roosevelt, and in 1933 the new President Roosevelt announced, His economic program is known as The New Doa, and what surprised analysts and observers was the speed with which the Now Doal plan was implemented, in which he carried out many measures of economic reform, which led to the recovery from the crisis in the beginning of 1939.

\section{The Second Axis:}

The history of fashion and fashion influenced by political and social conditions in the 1930s: The hotness of the New York Stock Exchange and the resulting frustration had a direct impact on what people wore in that era, and despite this, this era was a contradictory era in which the rich got rich and the poor got poorer, so the fashion became conservative Simple and therefore, elegant and elegant, as it was a way to escape from the painful reality through those who could afford it and deal with it, and on the other side, who is satisfied with just following this, the history of fashion and its impact on the political and social conditions in the 1930s can be monitored through five axes

The first axis: changes in the general pattern of fashion in the thirties.

The second axis: the prevailing color fashion in the thirties.

The third axis: the types of fabrics and raw materials used in the manufacture of clothes in the thirties:

The fourth axis: cinema and fashion in the thirties.

Axis V: The most famous fashion designers in the thirties. 


\section{The first axis: changes in the general pattern of fashion in the thirties:}

Fashion in the thirties became moderate, simple and practical, with elegance, sophistication and fitness, with a reservation resulting from the prevailing frustration, and moved away from his boldness and the recklessness of the twenties and turned to a more romantic view full of femininity: the distinctive form of this fashion or silhouette was close to the body, following its lines, the center in its natural place The shoulders are wide, the chest is low, the buttocks are defined and streamlined, the length of the jaws reaches the middle of the leg or the ankle in day clothes and the full length in evening clothes and if these are not the characteristics of the body, the mirror, especially with regard to the waist and buttocks, is trying to obtain it through Exaggeration in width of the shoulders by fillings of the shoulders or puffed sleeves or cornices until the waist and buttocks appear slimmer. : Through a modest budget, the share of fashion was not specified in it. The role of the middle-income woman was to maintain her elegance at the lowest cost that she could afford. She would sew her clothes herself from cheap fabrics such as cotton fabrics used in linens, following the same prevailing fashion lines that were inspired by fashion. Movie stars or designs that were on display in clothing stores, and she was helped by fashion magazines specializing in ready-made patterns such as McCall.

\section{The second axis: the prevailing color fashion in the thirties:}

The dominant colors were the calm colors, which were present in harmonious groups or variations, and the printed fabrics contained floral prints, geometric shapes, or the polka dot (Polka Dot), which was a large table in that period and the stripes, and most of the prints had a white background and that was intended Provide dyes.

\section{The third axis: the types of fabrics and materials used in the manufacture of clothes in} the thirties:

The tendency of women to sew their clothes due to the economic crisis was with the aim of saving and their inability to buy ready-made clothes, so the purchase of fabrics reduces the cost, so they buy fabrics either from specialized stores or through the mail through choosing the fabric from the catalogs for that.

-Fabrics used in making morning clothes: The fabrics used in the manufacture of morning clothes were made of natural fibers such as Cotton: it was used in a more practical way (instead of using it in linens) in the thirties, thanks to Chanel, which presented a group The entire work clothes were made of cotton, and the fabrics were either plain or printed. Dimity, a transparent lightweight cotton fabric, and Linen: it was printed most of the time. And Crepe: It was one of the distinctive fabrics in the thirties, which was easy to shape and gave the distinctive shape of fashion in that period of loose and flowability, and it was made of rayon (rayon), silk cotton, 
and it came in plain colors or printed with floral prints. And Pongee: It is a natural silk cloth and it was called Japanese silk. It was present in the colors of the material or printed. : Voile (Moile): It is a very thin and light fabric that hangs softly. It was made at that time from cotton or linen and comes in plain colors or small prints of flowers or dotted.: Dotted Swiss: It is a transparent cotton cloth decorated with small dots prominent from The fabric instead of being printed and because of its transparency, it is floated with a light cotton lining.Wool: It was present in its pure form or mixed with cotton or rayon to make it cheaper, lighter, smoother and wrinkle resistant.Chambray: It is a heavy blue denim fabric which is in Most of the time it is striped.Corduroy: It is a velvety fluff ribbed cotton fabric and comes in plain colors.

\section{Fourth Theme: Seminar Fashion in the Thirties:}

The collapse of the stock market and the frustration that resulted from it led people to turn to the cinema to help them relax and forget the harsh conditions they are going through, and this had a direct impact on fashion in that period as Hollywood stars and movie stars became the main source of fashion, and American fashion designers used movie stars To help them publish their designs at no cost, as cinema in that period was like advertising and marketing the modern fashion trends presented by movie costume designers such as Adrian or Scaparelli, who presented modern designs worn by Hollywood stars who have become fashion icons. To the whole world, like Marlene Dietrich, Katharine Hepburn, Joan Crawford, Greta Garbo and Gean Harlow.

\section{Theme 5: The most famous fashion designers in the thirties:}

The economic crisis and the Great Depression in the thirties affected the high-end sewing industry (Haute Couture) because of the inability of American customers to purchase orders for dresses as before the crisis, and a group of the most famous fashion designers appeared in the thirties who understood the nature of the period and tried to overcome the crisis through Enjoying people with charming, elegant and elegant designs such as: Elsa Schiaparelli) (19731890): She is an Italian fashion designer who gained fame in the period between the two world wars affected by the surrounding political conditions such as the economic crisis and the emergence of fascism in Germany, Italy and Spain and understood the nature of the period and presented Fun and charming designs, as she had a high appreciation for art and its schools such as surrealism and Dada, which had a clear impact on her designs, Scaparelli collaborated with Salvador Dalil, the surrealist artist in 1937, in many of her famous designs such as (Lobster Dress) who painted his print. By himself. 


\section{Results:}

1- History is an endless source of inspiration in the field of fashion and fashion design, so the study was important.

2- The Academy of History in General and the History of Fashion in particular Students The field of Fashion Arts as a source of inspiration.

3- The political, economic and social changes in the life of societies directly affect art in general and fashion in particular, which is an objective reflection of these changes.

4- It becomes a new trend of the disease in the thirties, influenced by the political and social conditions surrounding it and trying to escape from the painful reality, a fashion that expresses the femininity of the woman and increases her charm and attractiveness, for those who could afford it and deal with it, and on the other side who is satisfied with just following up.

5- By monitoring the change in the general pattern of fashion in the period of the thirties as a result of political and social conditions, it is found that

6- Through a modest budget, the share of fashion was not specified, in which the role of the middle-income woman was to maintain her elegance at the lowest cost she could afford.

7- Most of the prints had a white background and that was to provide pigments.

8- The tendency of women to sew their clothes due to the economic crisis was aimed at saving and their inability to buy ready-made clothes, so buying fabrics reduces the cost, so they buy fabrics either from specialized stores or by mail through choosing the fabric from the catalogs for that.

9- People turn to cinema to help them relax and forget the harsh conditions they are going through, and this had a direct impact on fashion in that period, as Hollywood stars and movie stars became the main source of fashion, and American fashion designers used movie stars to help them spread their designs without any cost.

10- The decline of the high-end tailoring industry (Haute Couture) due to the inability of American customers to purchase orders for dresses as before the crisis: A group of the most famous fashion designers appeared in the thirties who understood the nature of the period and tried to overcome the crisis by entertaining people with charming, elegant and elegant designs.

11- One of the most important fashion designers in the thirties who contributed to defining the trend of fashion in the thirties from the researcher's point of view was Elsa Schiaparelli, Madeleine Vionnet. 


\section{Recommendations:}

1- The need to pay attention to raising the efficiency of history curricula in colleges specialized in the field of fashion and to support them with pictures, and to review the websites of museums around the world, which display their contents of fashion and others on the information network.

2- Creating a website that includes the development of fashion history through the ages in order to be a reference for all art students.

3- Raising public awareness of the importance of studying history through the work of documentary television programs and specialized websites that permanently present the history of nations and their development in all fields, provided by specialists in studying the history of nations from specialized colleges and institutes.

4- Encouraging students to revive history in general and the history of fashion in particular, and to benefit from it by holding fashion shows adapted from history and displaying them in public places in order to spread awareness and raise the cultural level of fashion

\section{References}

1. Ahmed Hamdi Mahmoud: Beyond Art, General Book Authority, Cairo, 1993.

2. Ahmad Atiyah Allah: The Political and Economic Dictionary, Dar Al-Nahda Al-Arabiya, 1968.

3. Iman Muhammad Ahmad Hashem, (2014). Creativity and innovation in product design as a competitive advantage, International Design Journal, Volume 4, October issue.

4. Tahia Kamel Hussein, (2002) The History and Development of Fashion, Nahdet Misr Publishing House, Part 3

5. George Santillana; Translated by Mustafa, Those with a sense of beauty, The AngloEgyptian Library, Cairo, 1988.

6. Abdel Azim Ramadan, History of Europe and the World in the Modern Era, Egyptian Book Authority, Part 3, 1996.

7. Amr Mohamed Abdel-Qader Hedia, (2015) Design as a Creative Industry that Achieves the Creative Economy of the Levantine Countries, International Design Journal, Volume 5, January Issue.

8. Mahmoud Al-Bassiouni: Views on Modern Art, Dar Al Maaref, Cairo, 1961.

9. Mahmoud Al-Bassiouni: Culture and Education, Dar Al-Ma'arif, 1965.

10. Judith S Baughman; "The 1930s: Lifestyles and Social Trends,, Gale, 2001.

11. Brockman Helen ,L, : The Theory Of Fashion Design, London, 1965. 
12. Herchel, Chipp : Thearies Of Modem Art, University of Califomia Press, U.S.A, 1973.

13. Gini Stephans Frings:Fashion from concept to consumer 9thEdition,pearson, 2008.

14. Grou Mar goret : The Arts Of Costume, Second Edition, London, 1962 .

15. Joan Numm:Fashion and Costume 1200-2000, New York, 1990.

16. Richard Martin : Cubism And Fashion, The Metropolitan Museum Of Art, INC., New York .

17. StevenFaerm:Fashion Design Course, Barrons, 2008.

18. Sturm, Gieser, Lyle Roberts : Guide to Modem Clothing The Viking Press,USA. 1978.

19. Valerie De Givry : Art \& Mode, Editions Du Regard, Paris, 1998.

20. william Collins:" Webster's New world Dictionary"World Publishing CO. INC., New York, 1971.

21. Mirrahan Faraj ORABI, FASHION IS A CENTRAL TOOL TO BRING OUT THE DRAMATIC CHARACTER OF BRIDES, International Journal of Design and Fashion Studies, Vol. 1, No. 2, 2018, pp. 14-19.

22. Dina Muhammad ENAD, GRAPHIC DESIGN IS A LANGUAGE THAT PROMOTES CULTURAL AND AESTHETIC COMMUNICATION OF SOCIETY, International Journal of Design and Fashion Studies, Vol. 1, No. 2, 2018, pp. 20-28.

Received: January 14, 2019

Accepted: March 21, 2019 